\title{
Thermal Stability and Flame Resistance of the Coextruded Wood- Plastic Composites Containing Talc-Filled Plastic Shells
}

\author{
Runzhou Huang $\mathbb{D}^{1}{ }^{1}$ Xian Zhang, ${ }^{1}$ Zhilin Chen, ${ }^{2}$ Minli Wan, ${ }^{3}$ and Qinglin $W u \mathbb{D}^{4}$ \\ ${ }^{1}$ College of Materials Science and Engineering, Nanjing Forestry University, Nanjing 210037, China \\ ${ }^{2}$ Research Institute of Wood Industry, Chinese Academy of Forestry, Beijing 100091, China \\ ${ }^{3}$ School of Business Administration, Jiangxi University of Finance and Economics, Nanchang 330032, China \\ ${ }^{4}$ School of Renewable Natural Resources, Louisiana State University AgCenter, Baton Rouge, LA 70803, USA \\ Correspondence should be addressed to Qinglin Wu; qwu@agcenter.lsu.edu
}

Received 31 March 2020; Revised 2 June 2020; Accepted 16 June 2020; Published 1 July 2020

Academic Editor: Önder Pekcan

Copyright (c) 2020 Runzhou Huang et al. This is an open access article distributed under the Creative Commons Attribution License, which permits unrestricted use, distribution, and reproduction in any medium, provided the original work is properly cited.

\begin{abstract}
Talc is a popular filler for the fabrication of plastic composites. The presence of talc helps improve mechanical, thermal, and flame resistance properties of the composite. In this work, we report the influence of a talc-filled plastic shell layer on thermal stability and fire flammability of the core-shell structured wood high-density polyethylene (HDPE) composites manufactured through coextrusion. The result showed that morphological analysis of the char layer after combustion confirmed the formation of a continuous surface char layer with talc addition in the composites, helping block fire penetration and enhance overall fire resistance of the composites. The shell thickness averaged at $1.0 \pm 0.2 \mathrm{~mm}$, which represents a fair thick shell over a $10 \mathrm{~mm}$ thick WPC core layer. The surface of regular wood-filled HDPE showed large cracks, allowing more rapid fire penetration and reducing its fire resistance. At $800^{\circ} \mathrm{C}$, average residual weight for all composite was $21.5 \pm 13.8 \%$, most of which was attributed to the inorganic nonvolatile talc components. With the increase of talc level, THR values of coextruded WPC decreased from $302.47 \mathrm{MJ} / \mathrm{m}^{2}$ ( $5 \mathrm{wt} \%$ of talc) to $262.96 \mathrm{~kW} / \mathrm{m}^{2}$ ( $50 \mathrm{wt} \%$ of talc). When talc content in the shell layer was less than $25 \mathrm{wt} \%$, the flame resistance properties were slightly enhanced compared with the composites containing unmodified HDPE shells. When talc content in the shell exceeded $25 \mathrm{wt} \%$, the composite's total heat release and its rate substantially decreased.
\end{abstract}

\section{Introduction}

Coextruded core-shell structured wood-plastic composites (WPCs) as an emerging type of green structural materials have been developed to enhance performance of wood/natural fiber-reinforced polymer composites [1-3]. The combined use of wood fiber and plastic through core-shell structure design can help reduce overall composite costs and improve stiffness and biological resistance. They are also advantageous in terms of melt processing and weather resistance. The presence of a plastic shell (with large thermal expansion and low modulus) over a WPC core in the coextruded WPCs can, however, negatively affect overall fire flammability and thermal stability of the composite [4]. A shell layer composed of properly filled plastics can help reduce flammability and thermal degradation properties of the composite compared with coextruded WPC with unfilled shell and/or regular WPC without a core-shell structure.

Stabilization of shell layers using carbon nanotubes [5] as well as by combining wood and mineral fillers in the shell layer $[6,7]$ was attempted. Studies have also been conducted on the development of a stable shell layer over the coextruded WPCs by blending high-density polyethylene (HDPE) with additives (such as compatibilizers, photostabilizers, and nanosized $\mathrm{TiO}_{2}$ ) using combination of various minerals with wood [8] and precipitated calcium carbonate (PCC) [9] in the shell layer. Thermal expansion of the coextruded WPCs as function of thermal expansion and modulus of HDPE shells containing glass fibers was also studied by a finite element model. However, more cost-effective materials and design are still needed as shell layers for the coextruded WPC. 
WPCs are popular materials for interior panels for automobiles as well as construction deck boards. However, WPCs demonstrate poor fire resistance due to the extreme sensitivity of both plastic and wood to high temperatures. This limitation hinders the application of WPCs. Therefore, it is critical to improve WPCs' fire performance for overall safety and also to satisfy fire requirements and regulations, which will help to widen their industrial applications [10]. One possible method to improve WPC fire resistance is incorporation of fire retardants during, for example, the compression, extrusion, or injection molding stages of the WPC processing. Some of the most popular flame retardants are phosphorous based [11-15]. When ammonium polyphosphate (APP) was used as a WPC flame retardant, it formed a protective char layer, which significantly decreased flammability of the whole composite [16-19]. However, additional research and development of filler materials as flame-retardant shell layers for core-shell structured WPCs are still necessary.

Talc, a common mineral filler with a chemical formula $\mathrm{Mg}_{3} \mathrm{Si}_{4} \mathrm{O}_{10}(\mathrm{OH})_{2}$ and density of $\sim 2.75 \mathrm{~g} / \mathrm{cm}^{3}$, is often used in fabrication of reinforced plastic composites [20-22]. Talc-filled shells in coextruded WPCs can enhance their mechanical and thermal expansion performance [23]. The growth of inorganic filler systems for plastic has been particularly rapid owing to the demand for high-performance materials and filler's environmentally friendliness compared with chemical fire retardants.

Some work had been done to study the effects of talc fiber on mechanical properties of final composites. However, talc has not been widely used as a reinforced filler for polymer resin systems as a shell layer of coextruded WPC especially on thermal behavior, and only limited amount of data, especially on antiflammable properties, has been published on talc-filled HDPE composites with coextruded WPCs. Moreover, there is a lack of detailed investigation on the effect of talc at this point. Thus, the main objective this study described in this paper was to investigate the effect of incorporation of talc-filled shells on the thermal stability, morphology, and flammability of coextruded WPCs.

\section{Materials and Methods}

2.1. Raw Materials. Talc (with density of $\sim 2.8 \mathrm{~g} / \mathrm{cm}^{3}, 325-$ mesh average particle size, and $30 \mathrm{wt} \%$ absorption rate) was purchased from the Fibre Glast Developments Co. (USA). Pine wood flour (WF 20-mesh size) was acquired from American Wood Fibers Inc. (USA). High-density polyethylene (HDPE) of AD60 grade with $0.7 \mathrm{~g} / 10 \mathrm{~min}$ MFI at $190^{\circ} \mathrm{C}$ and $2.16 \mathrm{~kg}$ and density of $\sim 0.96 \mathrm{~g} / \mathrm{cm}^{3}$ was obtained from ExxonMobil Chemical Co. (USA). Maleic anhydridegrafted polyethylene (MAPE, Epolene ${ }^{\mathrm{TM}}$ G2608 grade) with $\mathrm{MFI}=\sim 6-10 \mathrm{~g} / 10 \mathrm{~min}\left(190^{\circ} \mathrm{C}\right.$ and $2.16 \mathrm{~kg}$ applied weight $)$, molecular weight $=65000 \mathrm{~g} / \mathrm{mol}$, and an acid number $=8$ mg of $\mathrm{KOH}$ per $\mathrm{g}$ of MAPE was bought from Eastman Chemical Co. (USA). Lubricant (TPW 306 grade) was from Struktol Co. (USA).

2.2. Composite Formulation. Several sample groups of coextruded WPCs were prepared for this work. The composite
TABLE 1: Formulation of core-shell (talc-filled shell) structured WPC.

\begin{tabular}{lcccccccc}
\hline & \multicolumn{4}{c}{ Core layer $(w t \%)^{\mathrm{a}}$} & \multicolumn{4}{c}{ Shell layer (wt\%) } \\
& Wood & HDPE & MAPE & Lub & Talc & HDPE & Talc & Colorant \\
\hline Core & 55 & 33 & 2 & 5 & 5 & 0 & 0 & 0 \\
A & 55 & 33 & 2 & 5 & 5 & 98 & 0 & 2 \\
B & 55 & 33 & 2 & 5 & 5 & 93 & 5 & 2 \\
C & 55 & 33 & 2 & 5 & 5 & 88 & 10 & 2 \\
D & 55 & 33 & 2 & 5 & 5 & 83 & 15 & 2 \\
E & 55 & 33 & 2 & 5 & 5 & 73 & 25 & 2 \\
F & 55 & 33 & 2 & 5 & 5 & 63 & 35 & 2 \\
G & 55 & 33 & 2 & 5 & 5 & 48 & 50 & 2 \\
\hline
\end{tabular}

${ }^{\mathrm{a}}$ Filler content was based on the total composite weight.

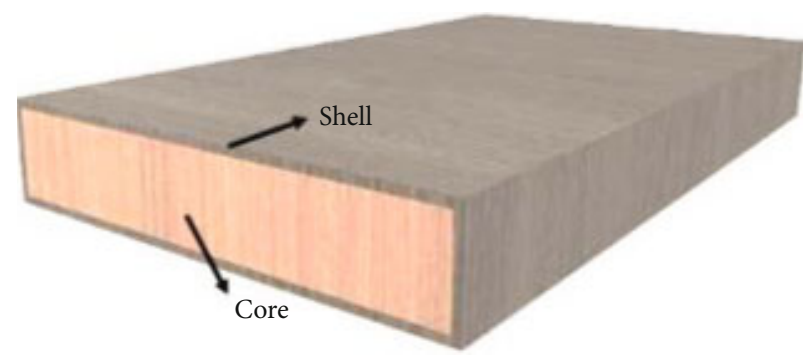

FIGURE 1: Coextruded core-shell WPCs with a talc-filled shell layer.

core consisted of HDPE, WF, lubricant, MAPE, and talc at $33: 55: 5: 2: 5$ weight ratio. The shell was made with HDPE and talc with talc fill rates of $0,5,10,15,25,35$, and $50 \%$ by weight. A total amount of $2 \mathrm{wt} \%$ of a colorant (relative to the shell material weight) was also added to the shell. The formulation of coextruded WPC is shown in Table 1.

2.3. Composite Manufacturing. Coextrusion experiment was performed using a coextrusion system [6] with two feeders for plastic pellets and wood fiber/lubricant/talc mixtures, respectively. The extrusion system consisted of a $32 \mathrm{~mm}$ conical Brabender (USA) and the Leistritz Micro-27 twin-screw extruders for the shell and for the core, respectively. Specially made die was used to obtain a profile with $13 \times 50 \mathrm{~mm}$ target cross-section size maintained by a vacuum sizer. The coextruded profiles were pulled by a downstream puller, going through a 2-meter-long water bath under constant water spray. Temperatures during coextrusion were 155 (at the feeder side), 160, 165, 170, 170, 170, 160, 150, 140, 135, and $155^{\circ} \mathrm{C}$ (at the die side) for the core. For different formulations, extrusion temperatures in the $150-165^{\circ} \mathrm{C}$ range were used for the shell.

\subsection{Characterization}

2.4.1. Composite Morphology Characterization. Sample morphologies were analyzed by scanning electron microscopy (SEM) (Model Hitachi S4800, Tokyo, Japan) operated at $15 \mathrm{kV}$ accelerating voltage. To prepare the SEM samples, the WPC samples were treated in liquid nitrogen for $10 \mathrm{~min}$ and then impact-broken to two separate pieces. The 


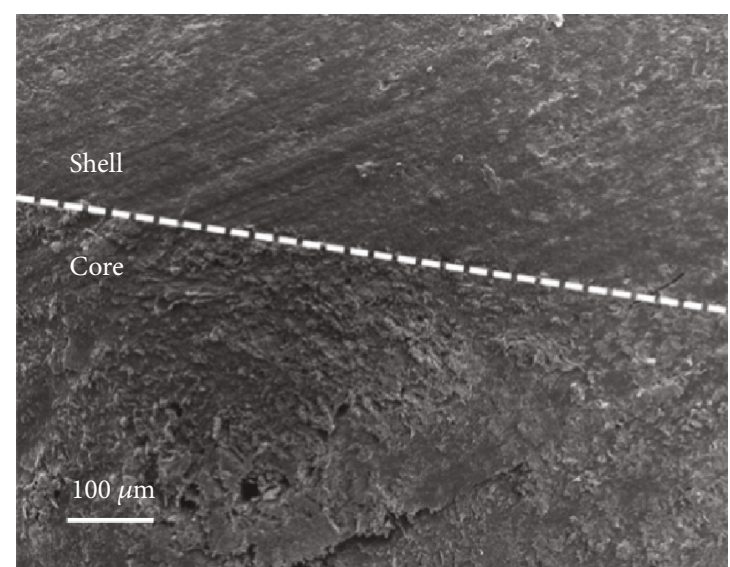

(a)

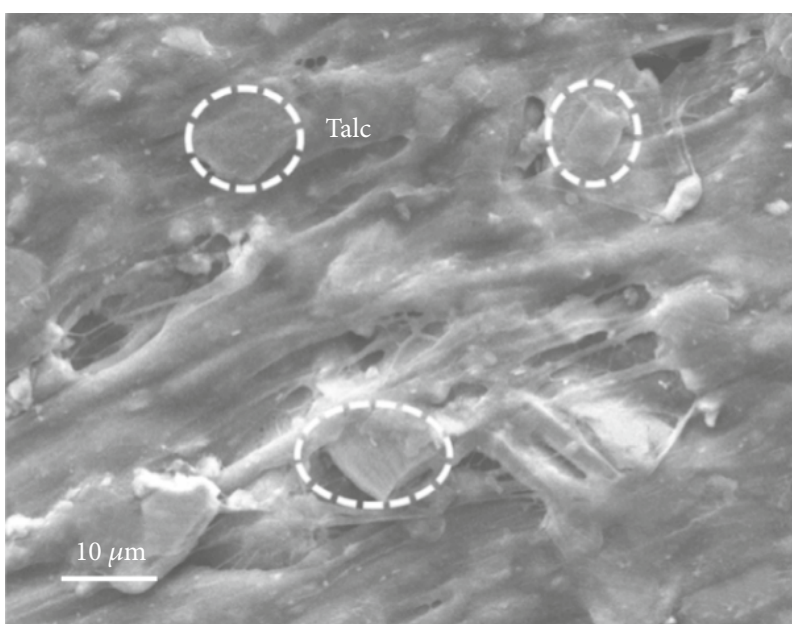

(b)

Figure 2: SEM micrographs of coextruded WPC with a talc-filled shell. (a) Core-shell interface. (b) Shell layer.

TABLE 2: Data obtained from TGA.

\begin{tabular}{|c|c|c|c|c|c|c|c|c|c|}
\hline Name & $T_{\mathrm{o}}\left({ }^{\circ} \mathrm{C}\right)$ & $\mathrm{WL}_{\mathrm{o}}(\%)$ & $T_{\mathrm{p}}\left({ }^{\circ} \mathrm{C}\right)$ & $\mathrm{WL}_{\mathrm{p}}(\%)$ & $T_{\mathrm{s}}\left({ }^{\circ} \mathrm{C}\right)$ & $\mathrm{WL}_{\mathrm{s}}(\%)$ & Residue (\%) & $T_{\mathrm{s}}-T_{\mathrm{o}}\left({ }^{\circ} \mathrm{C}\right)$ & $\mathrm{WL}_{\mathrm{s}}-\mathrm{WL}_{\mathrm{o}}(\%)$ \\
\hline AD60 & 459.0 & 30.13 & 470.5 & 65.74 & 480.4 & 95.42 & 0.83 & 21.4 & 65.29 \\
\hline Colorant & 446.3 & 15.83 & 458.2 & 26.70 & 674.9 & 44.75 & 52.23 & 228.6 & 28.92 \\
\hline Talc & 529.2 & 5.49 & 560.7 & 13.05 & 625.2 & 18.78 & 80.91 & 96 & 13.29 \\
\hline B & 462.2 & 35.31 & 469.6 & 58.63 & 480.9 & 89.08 & 5.93 & 18.7 & 53.77 \\
\hline $\mathrm{C}$ & 456.5 & 20.85 & 468.9 & 51.60 & 483.2 & 84.44 & 11.97 & 26.7 & 63.59 \\
\hline $\mathrm{D}$ & 461.0 & 26.01 & 470.0 & 50.43 & 480.6 & 78.36 & 13.58 & 19.6 & 52.35 \\
\hline $\mathrm{E}$ & 460.2 & 22.24 & 471.5 & 48.06 & 663.8 & 76.36 & 23.48 & 203.6 & 54.12 \\
\hline $\mathrm{F}$ & 460.5 & 19.21 & 472.0 & 42.73 & 675.6 & 68.95 & 30.93 & 215.1 & 49.74 \\
\hline G & 459.8 & 14.84 & 470.7 & 32.60 & 684.7 & 56.70 & 43.17 & 136.7 & 41.86 \\
\hline Core & 341.3 & 0.18 & 465.4 & 71.72 & 478.0 & 82.56 & 12.76 & 136.7 & 82.38 \\
\hline
\end{tabular}

fractured cross-sections were sampled and coated with Au to improve their conductivity during SEM runs.

2.4.2. Thermogravimetric Analysis (TGA). Thermal stability properties of various shells in comparison with the core composition were studied using a TA Instrument model Q50 analyzer (TA Inc., New Castle, DE, USA) with nitrogen. For each test, approximate $5 \mathrm{mg}$ of samples was tested at a heating rate of $5^{\circ} \mathrm{C} / \mathrm{min}$ and temperature range of $30-$ $800^{\circ} \mathrm{C}$. From each test run, the TG and differential TG (DTG) curves are plotted, from which characteristic temperatures were determined.

2.4.3. Flammability Test. Flammability tests were done using a Stanton Redcroft cone calorimeter manufactured by Fire Testing Technology Ltd. (London, UK). ISO 5660-1 standard procedure was implemented. Each sample was placed in an $\mathrm{Al}_{2} \mathrm{O}_{3}$ crucible ( $100 \mathrm{~mm}$ long and 100 wide) lined with $\mathrm{Al}$ foil. The assembly was mounted horizontally on the calorimeter loader and heated at $50 \mathrm{~kW} / \mathrm{m}^{2}$. The upper surface of the test sample corresponded to a temperature of $\sim 780^{\circ} \mathrm{C}$. Three measurements were performed for each sample group. Test result reproducibility was within $\pm 7 \%$.
The limiting oxygen index (LOI) was determined by igniting $10 \times 0.65 \mathrm{~cm}$ sample pieces in a glass tube containing $\mathrm{O}_{2} / \mathrm{N}_{2}$ mixture.

$$
\text { LOI }=\frac{\text { Volume of } \mathrm{O}_{2}}{\text { Volume of }\left(\mathrm{O}_{2}+\mathrm{N}_{2}\right)} \times 100 \%
$$

2.4.4. Surface Char Morphology Imaging. Digital images were taken from the sample surface before and after flame testing to contrast the surface char layers among different shell formulations.

\section{Results and Discussion}

3.1. Sketch Map of Coextruded WPCs. Figure 1 reveals a sketch map of coextruded WPC with core-shell structure (talc-loaded shell layer). The shell thickness averaged at $\mathbf{1 . 0}$ $\pm 0.2 \mathrm{~mm}$, which represents a fair thick shell over a $10 \mathrm{~mm}$ thick WPC core layer.

3.2. Morphology. SEM micrographs of coextruded WPCs containing talc-filled shells are shown in Figure 2. Figure 2(a) shows a significant difference in morphological 
characteristics between composite cores and shell layers. The core material showed a typical impact-fractured rough surface with wood fibers, while the shell layer with pure HDPE exhibited a smoother surface (Figure 2(a)). The shell layer bonded to the core layer well without showing apparent separation between the shell and the core. Talc platelets (shown in Figure 2(b)) are clearly visible on the fractured sample surfaces of the shell layer, and the platelets had both in-plane and out-of-plane orientations as shown. Talc pullout did not occur during the composite fracture judging by the absence of voids (Figure 2(b)).

3.3. Thermal Stability. Thermal stability data of pure and modified (with different talc contents) HDPE shells are presented in Table 2 and Figure 3. The TG and DTG curves of the shell layers containing different talc amounts are shown in Figure 3, in comparison with the WPC core. A strong DTG peak, appeared because of composite decomposition, was accompanied by a shoulder (shown with an arrow), which is typically attributed to talc decomposition in inert atmosphere. Similar peaks were observed for all samples, which indicates that even at different talc contents, composites had similar characteristics typical for polymer composites.

The TG curve indicated three obvious stages of pyrolysis. Accordingly, the DTG curve had two characteristic peaks (Figure 3). During the entire pyrolysis process, the initial temperature of pyrolysis with talc loading was close to $450^{\circ} \mathrm{C}$ (Table 2) and the initial temperature of pyrolysis for the core composite was $350^{\circ} \mathrm{C}$. The elements of the WPCs started to react in this stage. The first pyrolysis peaks were observed between $450^{\circ} \mathrm{C}$ and $560^{\circ} \mathrm{C}$, which represents a major stage of reaction wherein cellulose and hemicellulose began to decompose and lignin gradually softened, resulting in a number of products. The second pyrolysis peaks were observed between $470^{\circ} \mathrm{C}$ and $680^{\circ} \mathrm{C}$, which represents a stage of carbonization of materials. In this stage, the weight loss of all composites reached a maximum. The temperatures between the beginning of reaction and the second peak were in the range of $10 \sim 230^{\circ} \mathrm{C}$, and the weight loss was in the range of $10 \sim 90 \%$. As talc content in the composite increased, residual weight also increased. Residual weight of the shell composite containing $10 \mathrm{wt} \%$ talc was $11.97 \%$.

Data related to the composite decomposition is presented in Table 2. Decomposition onset was in the $459.0-462.2^{\circ} \mathrm{C}$ temperature range with the exception of the colorant and the core. Weight loss in this range, $\mathrm{WL}_{\mathrm{o}}$, was $\sim 58 \%$ for all talc-containing composites. HDPE containing $10 \mathrm{wt} \%$ of talc showed higher values, which indicates the fastest initial decomposition rate. $T_{\mathrm{p}}$ indicates that the maximum decomposition rate of talc-filled composites occurred at $\sim 470.5 \pm$ $1.2^{\circ} \mathrm{C}$. Decomposition of stand-alone talc occurred at higher temperature (equal to $560.7^{\circ} \mathrm{C}$ ). At these temperatures, composite weight losses were above $32 \%$. In this temperature range, because of the small talc content, weight loss associated with talc was $\sim 13 \%$. From peak to shift temperature, the composites exhibited rapid degradation in a narrow temperature range. Most shells showed a weight loss of almost $40 \%$ or higher at around $670^{\circ} \mathrm{C}$ as WL and $T_{\mathrm{s}}$ while the loading level was higher than $32 \mathrm{wt} \%$. At $800^{\circ} \mathrm{C}$, average residual
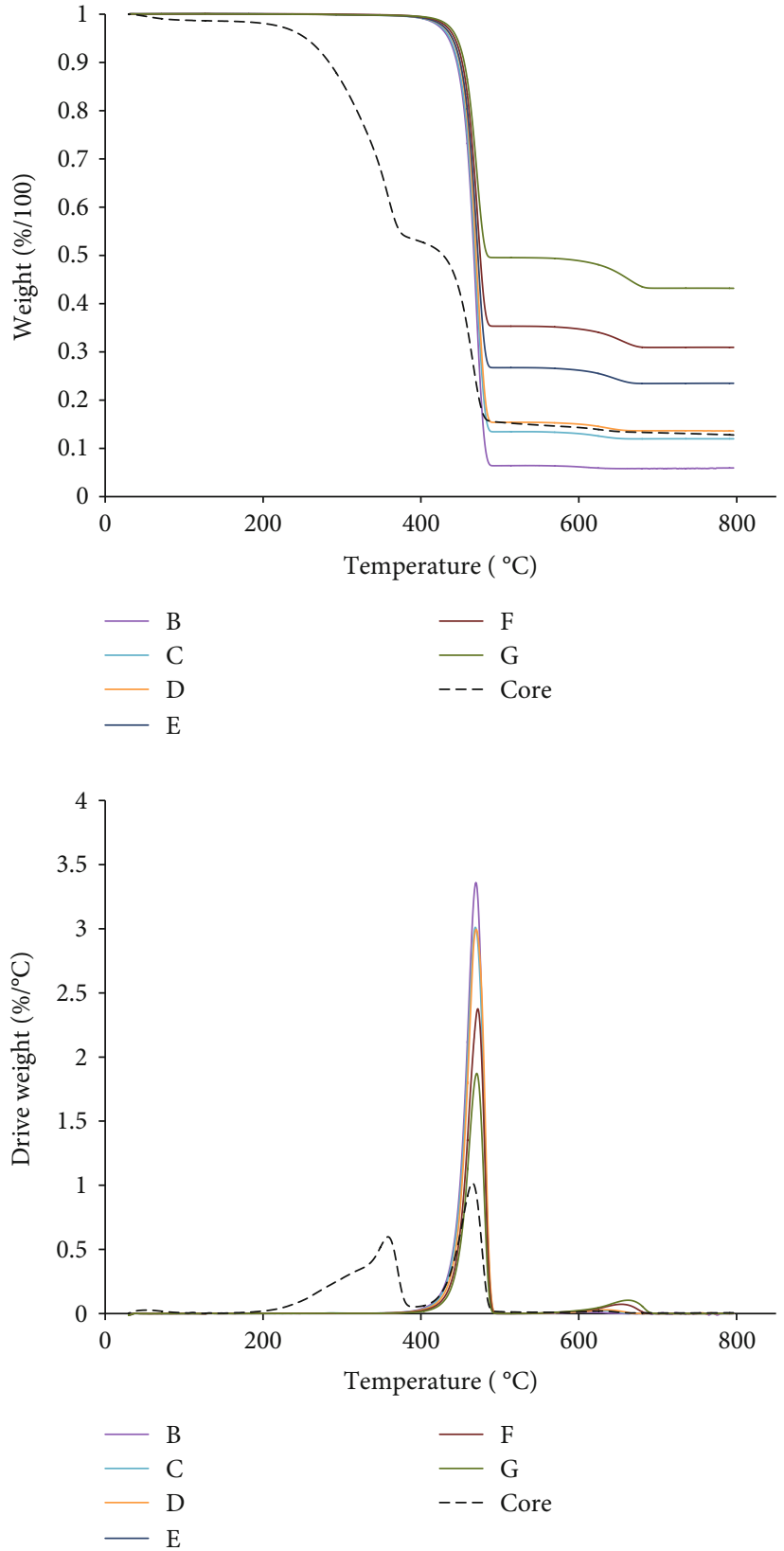

FIgURe 3: Decomposition curves obtained at a $5^{\circ} \mathrm{C} / \mathrm{min}$ heating rate of core-shell composites with different talc contents in the shell in comparison with a material containing just the core (dashed curves).

weight for all composite was $21.5 \pm 13.8 \%$, most of which was attributed to the inorganic nonvolatile talc components. Temperature and weight loss differences between the offset and shift points, $\left(T_{\mathrm{s}}-T_{\mathrm{o}}\right)$ and $\left(\mathrm{WL}_{\mathrm{s}}-\mathrm{WL}_{\mathrm{o}}\right)$, respectively, demonstrated most weight loss $(\sim 50 \%)$ occurred at $\sim 200^{\circ} \mathrm{C}$ for most talc-filled composites.

3.4. Flame Resistance. Test parameters including peak heat release rate (PHRR), total heat release (THR), average heat release rate (AHRR), average mass loss rate (AMLR), average effective heat of combustion (AEHC), and average specific extinction area (ASEA) were obtained from cone calorimetry 
TABLE 3: Summary of flammability performance.

\begin{tabular}{|c|c|c|c|c|}
\hline Talc content $(w t \%)^{\mathrm{a}}$ & $\operatorname{PHRR}^{\mathrm{b}}\left(\mathrm{kW} / \mathrm{m}^{2}\right)$ & $\operatorname{AHRR}\left(\mathrm{kW} / \mathrm{m}^{2}\right)$ & THR $\left(\mathrm{MJ} / \mathrm{m}^{2}\right)$ & $\operatorname{TSR}\left(\mathrm{m}^{2}\right)$ \\
\hline Core & $313.5(30.3)^{c}$ & $221.0(22.1)$ & $193.2(18.7)$ & $4167.0(398.1)$ \\
\hline 0 & $805.1(78.7)$ & $286.5(28.7)$ & $295.0(27.8)$ & $6466.9(637.7)$ \\
\hline 5 & $807.1(79.7)$ & $280.2(27.5)$ & $302.5(30.1)$ & $6476.0(653.2)$ \\
\hline 15 & $805.1(78.9)$ & $286.5(26.9)$ & $295.0(29.7)$ & $6466.9(612.8)$ \\
\hline 25 & $571.6(53.8)$ & $239.4(21.1)$ & $276.5(22.5)$ & $5938.6(578.9)$ \\
\hline 35 & $476.3(42.1)$ & $215.7(19.8)$ & $260.9(25.8)$ & $5036.8(511.2)$ \\
\hline 50 & $323.3(31.5)$ & 192.7 (19.6) & $262.1(26.3)$ & 4708.1 (381.9) \\
\hline
\end{tabular}

${ }^{\mathrm{a}}$ Filler content was based on the total composite weight. ${ }^{\mathrm{b}} \mathrm{PHRR}=$ peak heat release rate; AHRR = average heat release rate; THR $=$ total heat release; AMLR = average mass loss rate; ASEA = average specific extinction area; AEHC = average effective heat of combustion. ${ }^{\circ}$ Numbers in the parenthesis are standard deviation.

testing, and the data are shown in Table 3 and Figure 4 for the composites tested in this work.

The PHRR is a parameter that indicates fire size and its spread. For the composite containing over $15 \mathrm{wt} \%$ of talc in its shell spread, the PHRR values were significantly lower. The PHRR of the core alone was equal $313.48 \mathrm{~kW} / \mathrm{m}^{2}$. After the addition of the pure HDPE layer, however, the PHRR value of the composite increased to $805.11 \mathrm{~kW} / \mathrm{m}^{2}$, which indicates a negative effect of HDPE on WPC's flammability. Talc addition to the shell decreased the PHRR value of the composite. At talc shell content equal to $50 \mathrm{wt} \%$, the PHRR value of the composite was $59.8 \%$ lower than the PHRR of the unmodified plastic shell. In addition, THR and AMLR also decreased as more talc was added. Thus, the addition of talc in the shell layer slowed down the combustion process of the core-shell structured WPCs.

Total smoke rate data for our composites is shown in Figure 4(a). TSR increased with time. Coextruded WPCs containing shells with different talc amounts demonstrated improved (by 13-15\%) TSR values relative to unmodified WPCs. The composite core had a TSR of $4167 \mathrm{~kW} / \mathrm{m}^{2}$. The neat HDPE in the shell layer had a TSR of $6467 \mathrm{~kW} / \mathrm{m}^{2}$, and TSR values had little change for the talc-HDPE composites at 0,5 , and 15\% talc level. After talc filled the shells at $5 \mathrm{wt} \%$ in the shell layer, the TSR for talc-filled composites declined from $6476 \mathrm{~kW} / \mathrm{m}^{2}$ ( $5 \mathrm{wt} \%$ of talc) to $4708 \mathrm{~kW} / \mathrm{m}^{2}$ (50 wt\% of talc) as filler content increased. Figure 4 (b) shows correlation between heat release and time and reflects flammability performance of the talc-filled composites. The talc filler in coextruded WPCs had an important influence on fire performance. The HRR increased, and the surface of the composite was easier in pyrolysis, producing more combustible materials. On the contrary, the composite having lower HRR or peak of HRR had a good flammability performance.

In general, PHRR increased as filler content in the coextruded WPCs was increased (see Figure 4(b) and Table 3). For the core composite, the PHRR was $331.48 \mathrm{~kW} / \mathrm{m}^{2}$. The higher PHRR value at pure HDPE in the shell layer (compared with the core-only data) was $805.11 \mathrm{~kW} / \mathrm{m}^{2}$, which indicates a negative effect of pure plastic coating on flammability of the composite. Coextruded WPCs with shell filler content at $5 \mathrm{wt} \%$ of talc had a PHRR of $807.07 \mathrm{~kW} / \mathrm{m}^{2}$, rising up $0.24 \%$ compared with pure plastic. The PHRR decreased as talc content in the shell increased above $5 \mathrm{wt} \%$. AHRR values of pure and modified (with different talc contents) HDPE are shown in Table 3. The AHRR of a fixed WPC core was $221.04 \mathrm{~kW} / \mathrm{m}^{2}$. The AHRR for coextruded WPCs containing unmodified HDPE slightly increased relative to just WPC. The AHRR of the coextruded WPC containing HDPE with talc started decreasing after talc contents above $15 \%$. At talc contents in the shell equal to 35 and 50\%, AHRR values of the corresponding composites were 215.70 and $192.74 \mathrm{~kW} / \mathrm{m}^{2}$, respectively. These values are lower than those for just the core.

Time dependence of THR of the manufactured WPCs with different talc contents in the shell is shown in Figure 4(c). Talc addition to shells clearly increased THR. The WPC core had lower THR value (which was equal to 193.23 MJ/m² $\mathrm{m}^{2}$ than the WPC core layer containing unmodified HDPE (which was equal to $193.24 \mathrm{MJ} / \mathrm{m}^{2}$ ). THR values for the composites with 5 and $15 \mathrm{wt} \%$ of talc were very close to the THR values of the core material during the first $50 \mathrm{sec}-$ onds. Thus, total heat release was relatively stable with the increase of filler content. However, the THR for composites exhibited a decreasing trend with increased filler content after the talc loading levels reached to $5 \mathrm{wt} \%$. With the increase of talc level, THR values of coextruded WPC decreased from $302.47 \mathrm{MJ} / \mathrm{m}^{2} \quad(5 \mathrm{wt} \%$ of talc) to $262.96 \mathrm{~kW} / \mathrm{m}^{2}$ (50 $\mathrm{wt} \%$ of talc).

LOI values of all composites fabricated in this case enhanced as talc loading level in the shell layer enhanced (Figure 5). Before the torch flame was removed, core materials and core-shell structure composite with neat HDPE shells cannot be burned entirely and rapidly. When talc content in the shell layer was higher than $35 \mathrm{wt} \%$, the composites could not be totally burned even in the oxygen-rich combustion probably due to the protective shell layer.

3.5. Surface Char Morphology. Figure 6 shows composite surfaces photographed after the cone calorimetry test. A crisp char residue can be clearly seen for different WPC core composites (Figures 6(a) and 6(b)) with multiple broken pieces. The composite residue aggregated forming multiple cracks and holes. The cracks allowed more heat to penetrate deep into the composite, causing more complete combustion. On the other hand, the char layer, obtained for composites containing $25 \mathrm{wt} \%$ of talc in the shell (Figures 6(c) and 6(d)), was continuous with only some holes on the surface. Thus, this 


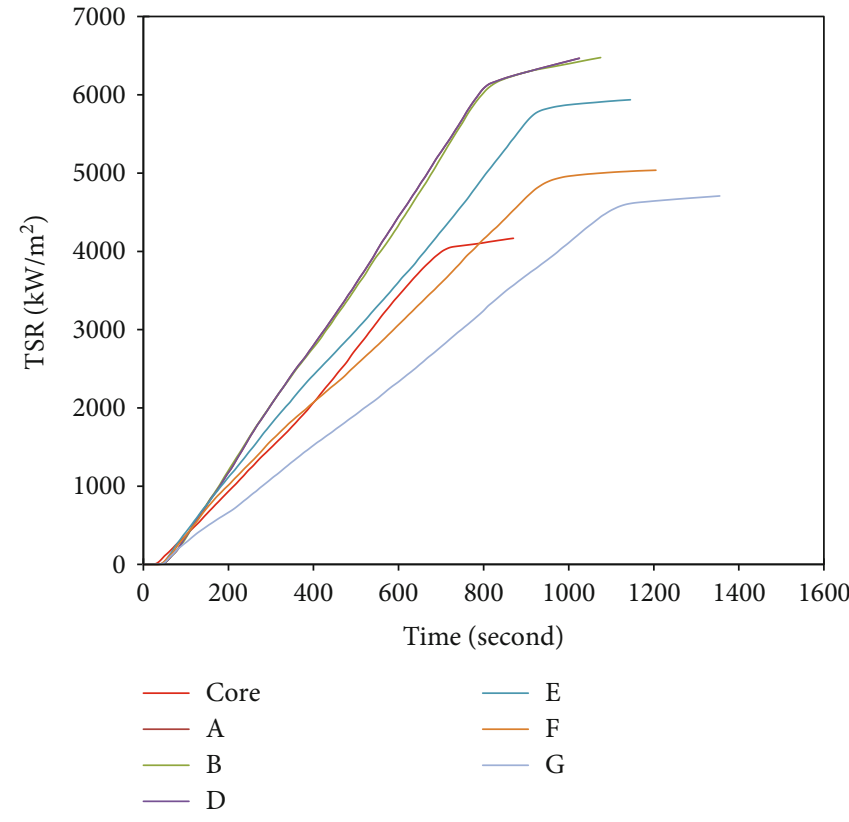

(a)

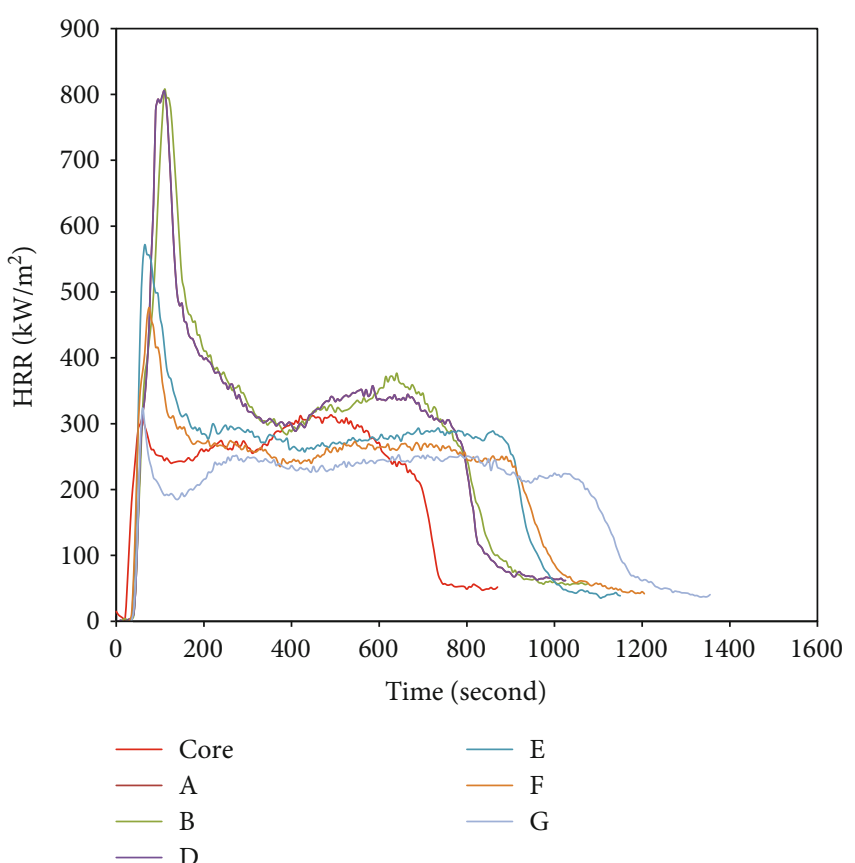

(b)

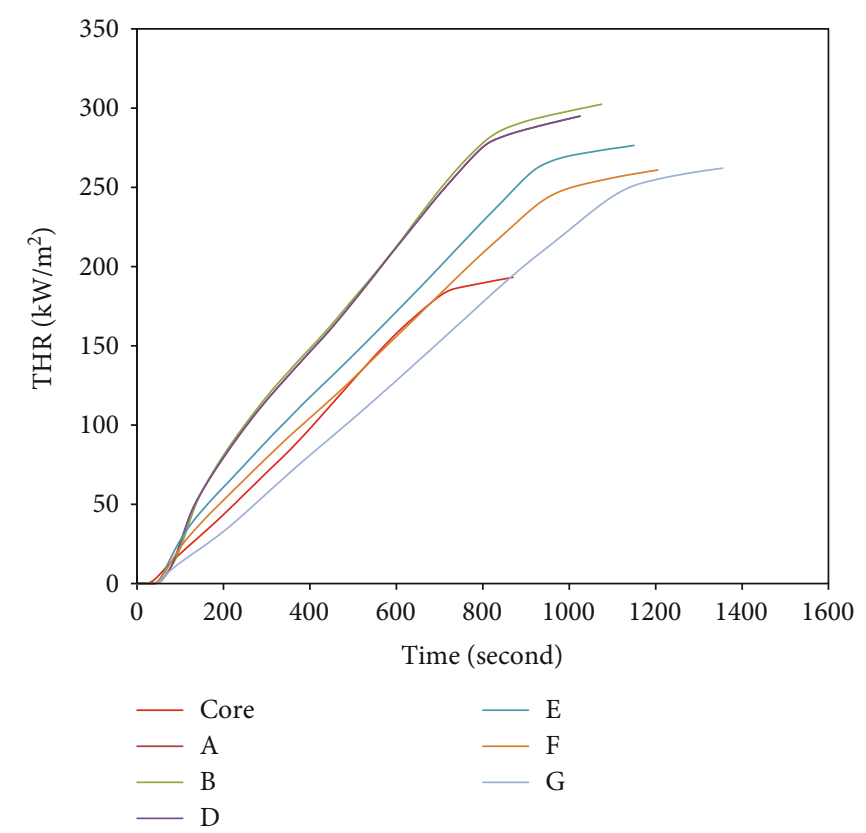

(c)

Figure 4: (a) Total smoke rate, (b) heat release rate, and (c) total heat release of the composites with different talc contents as a function of time.

cohesive and dense char layer blocked internal combustible gases and protected HDPE from flames. Such stable char provided a heat barrier, which also reduced the HRR and THR values (i.e., heat release).

\section{Conclusions}

The following conclusions can be drawn from the current study:
(1) A typical core-shell structured WPC was formed using shell layers filled with various amounts of talc over a regular WPC core

(2) The use of talc led to increased residual weight during TG analysis

(3) When talc content exceeded $25 \mathrm{wt} \%$, WPC's total heat release and its rate substantially decreased. PHRR and THR decreased as talc content in the shell 


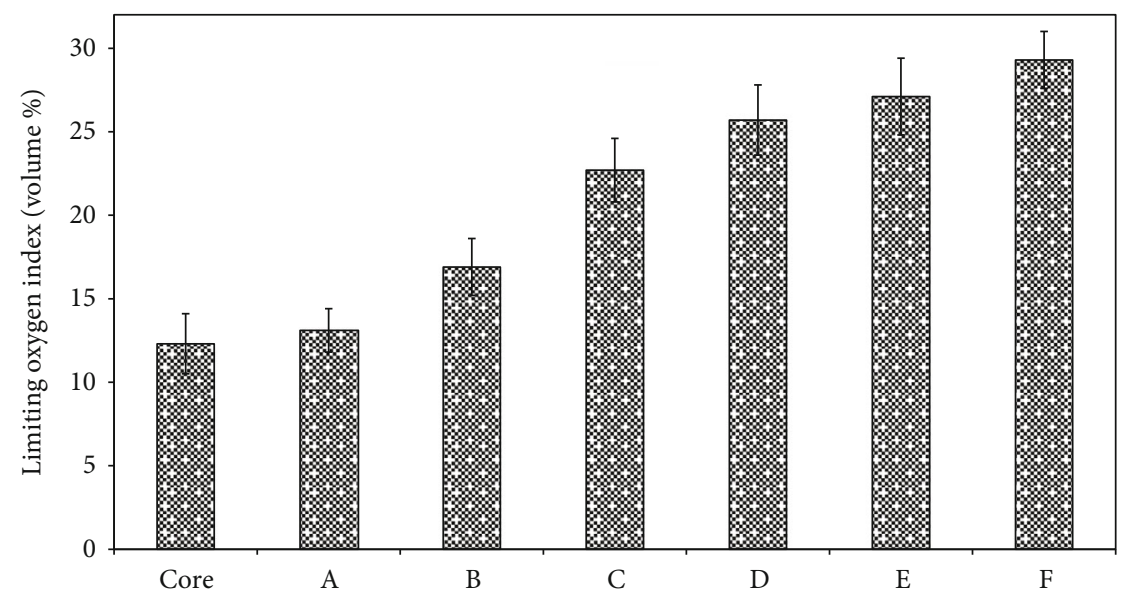

FIGURE 5: LOI of coextruded WPC with a talc-filled shell.

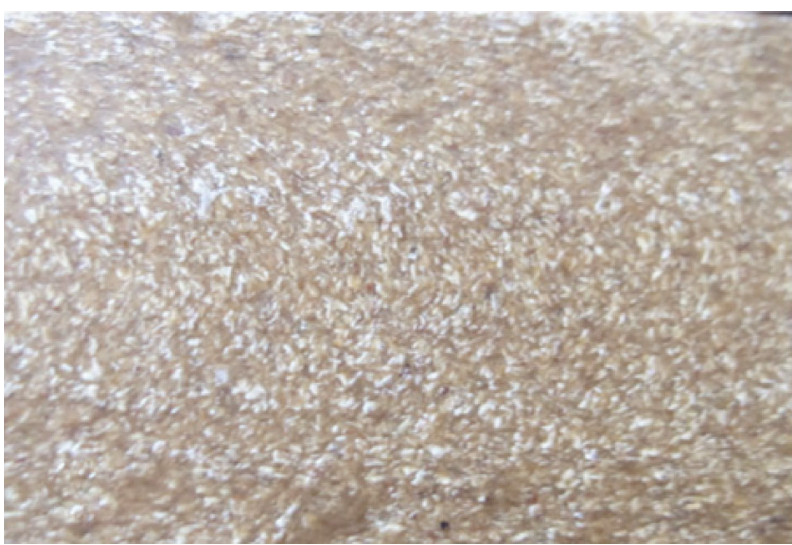

(a)

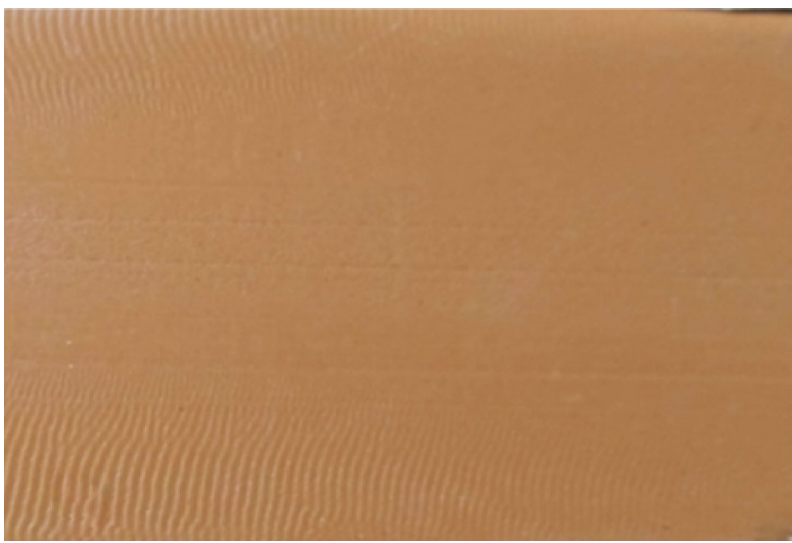

(c)

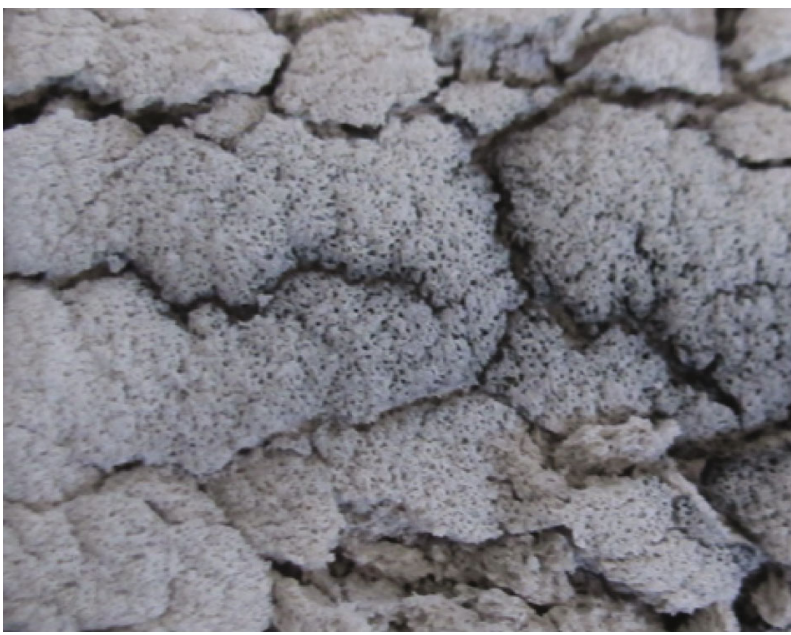

(b)

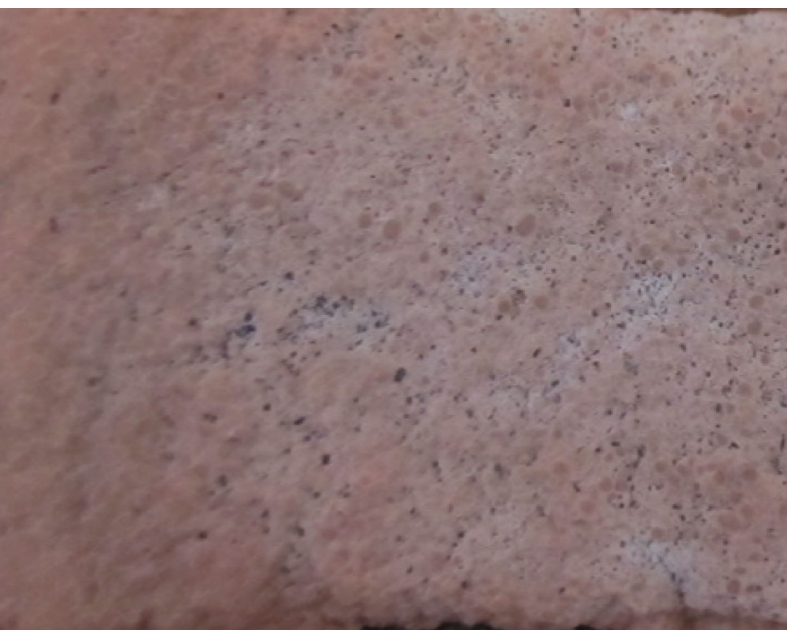

(d)

Figure 6: Photographs of the char residues on the samples subjected to the cone calorimetry: (a) core, (b) $20 \mathrm{wt} \%$ talc-filled shell layer, (c) core, and (d) core-shell structured composites with a HDPE shell. 
increased. Thus, combustion of the cure-shell composites was incomplete when talc was present, which is beneficial for their practical applications

(4) The surface of the composite produced more combustible materials in pyrolysis. With the increase of talc level, THR values of coextruded WPCs decreased from $302.47 \mathrm{MJ} / \mathrm{m}^{2}$ (5 wt\% of talc content) to $262.14 \mathrm{MJ} / \mathrm{m}^{2}$ (50 wt\% of talc content)

(5) Morphological analysis confirmed the formation of a continuous/dense surface char layer with talc addition in the composites which helped further enhance fire resistance of the coextruded WPCs

\section{Data Availability}

The data used to support the findings of this study are available from the corresponding author upon request.

\section{Conflicts of Interest}

The authors declare no conflict of interest.

\section{Acknowledgments}

This collaborative study was supported by the Louisiana Board of Regents (grant number LEQSF(2017-19)-RD-B-01); Major projects of Natural Science Foundation of Jiangsu University (18KJA220002); China Postdoctoral Science Foundation: Special Program (2017T100313); China Postdoctoral Science Foundation: General Program (2016M601821); Postdoctoral Science Foundation of Jiangsu Province: A Program (1601027A); and USDA NIFA McIntire Stennis project (grant number 1000017).

\section{References}

[1] B.-J. Kim, R. Huang, J. Han, S. Lee, and Q. Wu, "Mechanical and morphological properties of coextruded wood plastic composites with glass fiber-filled shell," Polymer Composites, vol. 37, no. 3, pp. 824-834, 2016.

[2] Q. Wu, K. Chi, Y. Wu, and S. Lee, "Mechanical, thermal expansion, and flammability properties of co-extruded wood polymer composites with basalt fiber reinforced shells," Materials and Design, vol. 60, pp. 334-342, 2014.

[3] R. Huang, W. Xiong, X. Xu, and Q. Wu, "Thermal expansion behavior of co-extruded WOOD-PLASTIC composites with glass-fiber reinforced shells," BioResources, vol. 7, no. 4, pp. 5514-5526, 2012.

[4] R. Huang, C. Mei, X. Xu, T. Kärki, S. Lee, and Q. Wu, "Effect of hybrid talc-basalt fillers in the shell layer on thermal and mechanical performance of co-extruded wood plastic composites," Materials, vol. 8, no. 12, pp. 8510-8523, 2015.

[5] S. Jin and L. M. Matuana, "Wood/plastic composites coextruded with multi-walled carbon nanotube-filled rigid poly(vinyl chloride) cap layer," Polymer International, vol. 59, pp. 648-657, 2009.

[6] F. Yao and Q. Wu, "Coextruded polyethylene and wood-flour composite: effect of shell thickness, wood loading, and core quality," Journal of Applied Polymer Science, vol. 118, no. 6, pp. 3594-3601, 2010.

[7] R. Huang, Y. Zhang, X. Xu, D. Zhou, and Q. Wu, "Effect of hybrid mineral and bamboo fillers on thermal expansion behavior of bamboo fiber and recycled polypropylenepolyethylene composites," BioResources, vol. 7, pp. 45634574, 2012.

[8] N. Stark and L. Matuana, "Co-extrusion of WPCs with a clear cap layer to improve color stability," in Proceedings of 4th Wood Fiber Polymer Composites International Symposium, pp. 1-13, Bordeaux, France, 2009.

[9] B. J. Kim, F. Yao, G. Han, Q. Wang, and Q. Wu, "Mechanical and physical properties of core-shell structured wood plastic composites: effect of shells with hybrid mineral and wood fillers," Composites Part B: Engineering, vol. 45, no. 1, pp. 1040-1048, 2013.

[10] Y. Fang, Q. Wang, C. Guo, Y. Song, and P. A. Cooper, "Effect of zinc borate and wood flour on thermal degradation and fire retardancy of polyvinyl chloride (PVC) composites," Journal of Analytical and Applied Pyrolysis, vol. 100, pp. 230-236, 2013.

[11] Y. Arao, S. Nakamura, Y. Tomita, K. Takakuwa, T. Umemura, and T. Tanaka, "Improvement on fire retardancy of wood flour/polypropylene composites using various fire retardants," Polymer degradation and stability, vol. 100, pp. 79-85, 2014.

[12] M. B. A. Bakar, Z. A. M. Ishak, R. M. Taib, H. D. Rozman, and S. M. Jani, "Flammability and mechanical properties of wood flour-filled polypropylene composites," Journal of Applied Polymer Science, vol. 116, 2010.

[13] N. Ayrilmis, J. T. Benthien, H. Thoemen, and R. H. White, "Properties of flat-pressed wood plastic composites containing fire retardants," Journal of Applied Polymer Science, vol. 122, no. 5, pp. 3201-3210, 2011.

[14] Z. X. Zhang, J. Zhang, B. X. Lu, Z. X. Xin, C. K. Kang, and J. K. Kim, "Effect of flame retardants on mechanical properties, flammability and foamability of PP/wood-fiber composites," Composites Part B: Engineering, vol. 43, no. 2, pp. 150-158, 2012.

[15] J. Zheng, B. Li, C. Guo, Q. Wu, and Y. Wang, "Flame-retardant properties of acrylonitrile-butadiene-styrene/ wood flour composites filled with expandable graphite and ammonium polyphosphate," Journal of Applied Polymer Science, vol. 131, no. 10, article 40281, 2014.

[16] L. Zhou, C. Guo, and L. Li, "Influence of ammonium polyphosphate modified with 3-(methylacryloxyl) propyltrimethoxy silane on mechanical and thermal properties of wood flour-polypropylene composites," Journal of Applied Polymer Science, vol. 122, no. 2, pp. 849-855, 2011.

[17] B. Li and J. He, "Investigation of mechanical property, flame retardancy and thermal degradation of LLDPE-wood-fibre composites," Polymer Degradation and Stability, vol. 83, no. 2, pp. 241-246, 2004.

[18] H. Seefeldt, U. Braun, and M. H. Wagner, "Residue Stabilization in the Fire Retardancy of Wood-Plastic Composites: Combination of Ammonium Polyphosphate, Expandable Graphite, and Red Phosphorus," Macromolecular Chemistry and Physics, vol. 213, no. 22, pp. 2370-2377, 2012.

[19] G. Bai, C. Guo, and L. Li, "Synergistic effect of intumescent flame retardant and expandable graphite on mechanical and flame-retardant properties of wood flour-polypropylene composites," Construction and Building Materials, vol. 50, pp. 148-153, 2014. 
[20] S. Karrad, J. M. Cuesta, and A. Crespy, "Influence of a fine talc on the properties of composites with high density polyethylene and polyethylene/polystyrene blends," Journal of Materials Science, vol. 33, no. 2, pp. 453-461, 1998.

[21] R. J. Clark and O. Noel, Recent advances in talc-reinforced wood-plastic composites, 8th International Conference on Woodfibre-Plastic Composites, Madison, Wisconsin, 2005.

[22] J. I. Weon and H. J. Sue, "Mechanical properties of talc- and $\mathrm{CaCO} 3$-reinforced high-crystallinity polypropylene composites," Journal of Materials Science, vol. 41, no. 8, pp. 22912300, 2006.

[23] R. Huang, B. J. Kim, S. Lee, Y. Zhang, and Q. Wu, "Coextruded wood-plastic composites with talc-filled shells: morphology, mechanical, and thermal expansion performance," BioResources, vol. 8, no. 2, pp. 2283-2299, 2013. 